\title{
Adjunctive agomelatine therapy in the treatment of acute bipolar II depression: a preliminary open label study
}

This article was published in the following Dove Press journal:

Neuropsychiatric Disease and Treatment

14 February 2013

Number of times this article has been viewed

\author{
Michele Fornaro' \\ Michael J McCarthy ${ }^{2,3}$ \\ Domenico De Berardis ${ }^{4}$ \\ Concetta De Pasquale! \\ Massimo Tabaton ${ }^{5}$ \\ Matteo Martino ${ }^{6}$ \\ Salvatore Colicchio ${ }^{7}$ \\ Carlo Ignazio Cattaneo ${ }^{8}$ \\ Emanuela D'Angelo' \\ Pantaleo Fornaro ${ }^{6}$ \\ 'Department of Formative Sciences, \\ University of Catania, Catania, Italy; \\ ${ }^{2}$ Department of Psychiatry, Veteran's \\ Affairs San Diego Healthcare System, \\ ${ }^{3}$ University of California San Diego, \\ La Jolla, CA, USA; ${ }^{4}$ Department of \\ Mental Health, Psychiatric Service \\ of Diagnosis and Treatment, \\ "ASL 4", Teramo, Italy; ${ }^{5}$ Department \\ of Internal Medicine and Medical \\ Specialties, University of Genova, \\ Genoa, Italy; ${ }^{6}$ Department of \\ Neurosciences, Section of Psychiatry, \\ University of Genova, Genoa, Italy; \\ ${ }^{7}$ Unit of Sleep Medicine, Department \\ of Neuroscience, Catholic University, \\ Rome, Italy; ${ }^{8}$ National Health System, \\ "ASL I 3", Novara, Italy; ' National \\ Health System, “ASL 3”, Genoa, Italy
}

Purpose: The circadian rhythm hypothesis of bipolar disorder (BD) suggests a role for melatonin in regulating mood, thus extending the interest toward the melatonergic antidepressant agomelatine as well as type I (acute) or II cases of bipolar depression.

Patients and methods: Twenty-eight depressed BD-II patients received open label agomelatine ( $25 \mathrm{mg} /$ bedtime) for 6 consecutive weeks as an adjunct to treatment with lithium or valproate, followed by an optional treatment extension of 30 weeks. Measures included the Hamilton depression scale, Pittsburgh Sleep Quality Index, the Clinical Global Impression Scale-Bipolar Version, Young Mania Rating Scale, and body mass index.

Results: Intent to treat analysis results demonstrated that 18 of the 28 subjects $(64 \%)$ showed medication response after 6 weeks (primary study endpoint), while 24 of the 28 subjects $(86 \%)$ responded by 36 weeks. When examining primary mood stabilizer treatment, 12 of the $17(70.6 \%)$ valproate and six of the $11(54.5 \%)$ lithium patients responded by the first endpoint. At 36 weeks, 14 valproate treated (82.4\%) and 10 lithium treated (90.9\%) subjects responded. At 36 weeks, there was a slight yet statistically significant $(P=0.001)$ reduction in body mass index and Pittsburgh Sleep Quality Index scores compared to respective baseline values, regardless of mood stabilizer/outcome. Treatment related drop-out cases included four patients (14.28\%) at week 6 two valproate-treated subjects with pseudo-vertigo and drug-induced hypomania, respectively, and two lithium-treated subjects with insomnia and mania, respectively. Week 36 drop outs were two hypomanic cases, one per group.

Conclusion: Agomelatine $25 \mathrm{mg}$ /day was an effective and well-tolerated adjunct to valproate/ lithium for acute depression in BD-II, suggesting the need for confirmation by future double blind, controlled clinical trials.

Keywords: bipolar disorder type-II, acute bipolar depression, agomelatine, adjunctive treatment

\section{Introduction}

Although the Diagnostic and Statistical Manual for Mental Disorders-Fourth Edition $(\mathrm{DSM}-\mathrm{IV})^{1}$ proposes mania as the hallmark of bipolar disorder (BD), depression is the most enduring aspect of the illness, ${ }^{2}$ requiring intense treatment efforts. ${ }^{3}$ Moreover, the majority of patients with bipolar depression fail to respond adequately to pharmacotherapy. ${ }^{4}$ For this reason, novel treatments for bipolar depression are needed, and despite being controversial due to the uneven results reported in acute and long-term follow-up clinical trials, antidepressant medications are commonly used for bipolar depression. ${ }^{5}$ The antidepressant agomelatine is a norepinephrine and dopamine disinhibitor drug, acting as a 5-HT2C/2B serotonin receptor antagonist and
Correspondence: Michele Fornaro Department of Formative Sciences at the University of Catania, Via Teatro Greco, 84, 95I24, Catania, Italy

Tel 39-347-4|40003

Fax 39-095-316792

Email dott.fornaro@gmail.com 
MT1/MT2 melatonin receptor agonist proven effective in the treatment of major depressive disorder (MDD). ${ }^{6-9}$

In pilot studies of type I BD (BD-I), agomelatine showed interesting results. ${ }^{10,11}$ Yet, to the best of our knowledge, no equivalent information has been provided about depression in type II BD (BD-II). Because there are important differences between BD-I and BD-II in terms of prevalence, clinical course, and antidepressant treatment implications, the use of agomelatine in the latter condition also warrants investigation.

The conceptualization of BD as a disorder of cycling, possibly based on disturbances in circadian rhythms, has been suggested for centuries. Reports of impaired daily rhythms in "emotional disturbances" date back to Hippocrates, Galen, Aretaeus of Cappadocia [“...vital tone was subject to typical circadian variations"], and later Kraepelin. ${ }^{12}$ However, it was not until after the discovery of melatonin in 1958 that the link between the pineal gland and affective disorders, considered by 17 th century Cartesian theorists, found scientific biological support. ${ }^{13}$ More recently, these observations have been articulated into specific hypotheses of circadian rhythms as the bases for mood disorders. ${ }^{14,15}$ Presently, changes in sleep are included in the DSM-IV criteria for major depressive episodes, including those associated with BD, and sleep patterns have been proposed as predictors of manic relapses in BD. ${ }^{16}$ Melatonergic modulation has been shown to be relevant in regulating circadian rhythms and sleep patterns, both in $\mathrm{MDD}^{17,18}$ and $\mathrm{BD},{ }^{19}$ and recent evidence suggests an association between 5 HTR $2 \mathrm{C}$ gene polymorphisms and BD. ${ }^{20}$ Therefore, the circadian rhythm system represents a rational target for novel antidepressant medications aiming to address these clinical features of $\mathrm{BD},{ }^{21}$ and due to its unique receptor binding profile, considerable interest has been generated around the use of agomelatine.

The principal aim of this open label pilot study was to assess the efficacy and safety of adjunctive agomelatine pharmacotherapy in the treatment of acute major depression in BD-II. As secondary aims, we examined whether there were differences in sleep and/or body mass associated with agomelatine treatment, and whether any of these outcomes were differentially associated with concomitant lithium or valproate therapy.

\section{Methods}

\section{Participants}

Participants aged 18-65 years old were recruited by five experienced physicians between November 2010 and May 2012 through referrals to two main private outpatient practice centers in Italy (Genoa and Pisa). Patients were referred by general practitioners, psychiatrists, or self-referral. All met the DSM-IV criteria for a primary diagnosis of BD-II and a current major depressive episode, assessed by the means of the Structured Clinical Interview for DSM-IV Axis-I Disorders. $^{22}$ Additional inclusion criteria were a Hamilton Depression Rating-Scale 17-item (HAM-D-17) ${ }^{23}$ baseline score $\geq 18$; negative history for adrenal, thyroid, or liver diseases; and continuously therapeutic blood levels of lithium or valproate for at least 6 months. Exclusion criteria included (I) lifetime diagnosis of BD-I, schizophrenia, or other psychotic disorders, rapid-cycling or seasonal patterns, history of treatment-resistant depression (defined as non-response to two consecutive treatments of at least 4 weeks each with two different classes of antidepressants), Axis-II comorbidity (including mental retardation), and alcohol/drug use disorders; (II) severe medical comorbidities, including organic brain syndrome, clinically significant drug interactions (eg, ciprofloxacin), pregnancy, nursing, or a woman of childbearing potential who declined the use of an adequate contraceptive; (III) concomitant use of another mood altering medication in the previous 2 weeks, or 4 weeks in the case of fluoxetine (low doses of benzodiazepines [eg, lorazepam $\leq 2.5 \mathrm{mg} /$ day] were allowed during the first 2 weeks); and (IIII) concomitant psychological treatment. Written informed consent was obtained from all patients prior to enrollment in the study after procedures had been fully explained by a senior study coordinator active in patients' recruitment and evaluation. A total of 50 subjects were initially screened, and 28 were enrolled in the study $(\mathrm{F} / \mathrm{M}=17 / 11)$. Excluded cases included those with suboptimal mood stabilizer blood levels $(n=16)$, those using concomitant pharmacotherapies not allowed by the study protocol $(n=5)$, and those with a serious medical illness (Gilbert's syndrome, $\mathrm{n}=1$ ). Of the 28 subjects who participated, 17 (60.7\%) were on valproate and 11 (39.3\%) were taking lithium as their primary mood stabilizer therapy.

\section{Study design}

The efficacy of agomelatine as an adjunct to valproate (blood levels of $50-125 \mu \mathrm{g} / \mathrm{ml}$ ) or lithium (blood levels $0.6-1.1 \mathrm{mmol} / \mathrm{L}$ ) in the treatment of an acute BD-II major depressive episode was addressed using a 6 week open parallel-group design. No blind assessment or placebo controls were adopted, and the patients were regularly monitored for safety, with clear instructions to report any unexpected adverse events (AEs), including mood changes, to their treating physician at the earliest possible time. 


\section{Pharmacotherapy}

A fixed dose of agomelatine was used during the entire study ( $25 \mathrm{mg}$ at bedtime: 9:00-10:00 pm). Higher doses (eg, $50 \mathrm{mg}$ /day) were excluded due to the preliminary nature of the study according to safety considerations. During the initial period of 6 weeks, a psychiatrist performed clinical evaluations every 2 weeks on each subject. Thereafter, the patients who continued the trial were evaluated every 6 weeks until week 36 .

\section{Clinical assessment}

Demographic and clinical characteristics were recorded at baseline; the HAM-D-17 was the primary measure of mood. In all cases, "response" was defined as $>50 \%$ decrease in severity from the baseline HAM-D-17 score. Secondary measures were the Severity and Impression modules of the Clinical Global Impression Scale-Bipolar Version ${ }^{24}$ starting at the second week, the Young Mania Rating Scale (YMRS), ${ }^{25}$ and the Pittsburgh Sleep Quality Index (PSQI) ${ }^{26}$ which is a self-report instrument used to subjectively measure sleep across seven domains: quality, latency, duration, efficiency, disturbances, use of medication, and daytime somnolence. The scale is designed to assess both the initial quality and ongoing comparative measurements of sleep quality, and has a reliability Cronbach's alpha $=0.83$.

At every appointment, an assessment, including general and psychiatric clinical examinations, was performed. These included measurements of blood pressure, heart rate, and body mass index (BMI). Routine laboratory tests included monitoring of liver functioning (safety, including liver enzyme levels, was a secondary endpoint of the study) and blood levels of lithium or valproate. All AEs experienced by participants were recorded at each study visit, based on the clinical judgment of the investigator(s). Due to the explorative nature of the study and safety considerations, whenever an AE occurred (any degree of severity), this was considered grounds for agomelatine discontinuation by the investigators. In these cases, subjects were excluded from further study.

\section{Statistical analysis}

The a priori sample size requirement for the study was calculated to be at least 12 in each of the two mood stabilizer groups ( $\geq 24$ patients in total), based on considerations described previously for non-randomized pilot studies. ${ }^{27}$ All statistical analyses were performed using IBM $^{\circledR}$ SPSS $^{\circledR}$ Statistics ${ }^{\circledR}$ V.21.0.0 for Microsoft ${ }^{\circledR}$ Windows ${ }^{\circledR} 8$ Release Preview, Build 8400 . Since data followed a normal distribution, they were assessed using the Shapiro-Wilk test. Parametric comparative analysis for demographic, clinical, and course characteristics of the two groups were performed using a Student's two-tailed $t$-test for the continuous variables, and $\chi^{2}$ analysis for categorical variables, performing bivariate correlation analysis for selected metrics. Significance was set at $P<0.05$. Intent to treat analysis was performed for efficacy in those patients who took at least one capsule of study medication and had at least one valid postbaseline efficacy evaluation, either on the study medication or within 3 days of drug discontinuation.

\section{Results \\ Patient characteristics}

Baseline demographic and clinical characteristics of the study subjects are shown in Table 1. There were no significant differences in patient characteristics between the lithium and valproate treated subjects, although some numerical differences may have led to statistical significance with a larger, "nonpilot," sample size. All were diagnosed with BD-II, but many had secondary psychiatric disorders. Inter-rater reliability on the DSM-IV diagnosis indicated substantial agreement among the raters (Cohen's $\kappa=0.75[P<0.0001], 95 \% \mathrm{CI}=0.65-0.37$ ). By adopting a conservative definition of severe depression of HAM-D-17 scores $>28^{28}$, it was found that five patients $(17.9 \%)$ were severely depressed at study entry $(n=4[23.5 \%]$ for valproate and $\mathrm{n}=1[9.1 \%]$ for lithium).

\section{Primary outcomes}

Using intent to treat analysis, 12 of the 17 valproate treated $(70.6 \%)$ and 6 of the 11(54.5\%) lithium treated patients demonstrated clinical response to agomelatine augmentation at the 6 week primary study endpoint. Six valproate and one lithium treated patients ( $25 \%$ of the total) responded as early as the second week of treatment. Secondary analyses conducted at the 6 week assessment are shown in Table 2 . At the 36 week endpoint, 14 of the 17 (82.4\%) valproate treated and 10 of the $11(90.9 \%)$ lithium treated subjects had a clinical response.

\section{Secondary outcomes}

PISQ scores were significantly reduced after 6 weeks compared to baseline $(\mathrm{t}=6.738$ [27]; $P<0.001)$, and PISQ scores remained lower at week $36(\mathrm{t}=3.777$ [27]; $P=0.001)$. The PISQ reduction was similar in both the valproate and lithium groups, and occurred independently of therapeutic response at weeks 6 or 36 . At week 36 , a slight yet statistically significant $(\mathrm{t}=3.777 ; \mathrm{df}=27 ; P<0.001)$ reduction in BMI score was 
Table I Baseline characteristics of the patients included in the study

\begin{tabular}{|c|c|c|c|c|c|}
\hline & $\begin{array}{l}\text { Included set } \\
\mathbf{N}=\mathbf{2 8}\end{array}$ & $\begin{array}{l}\text { Agomelatine }+ \\
\text { valproate group } \\
N=17(60.7 \%)\end{array}$ & $\begin{array}{l}\text { Agomelatine + } \\
\text { lithium group } \\
\mathbf{N}=\text { I I }(39.3 \%)\end{array}$ & $\begin{array}{l}\text { F or } \chi^{2} \\
(d f=2)\end{array}$ & $P$ \\
\hline Sex F/M & $|7 /| \mid$ & $9 / 8$ & $8 / 3$ & $0.295(1)$ & ns \\
\hline $\begin{array}{l}\text { Age in years, } \\
\text { Mean (SD); (range) }\end{array}$ & $\begin{array}{l}41.29 \pm 13.60 \\
(21-64)\end{array}$ & $\begin{array}{l}41.94 \pm 13.94 \\
(23-64)\end{array}$ & $\begin{array}{l}40.27 \pm 13.66 \\
(2 I-6 I)\end{array}$ & 0.174 & ns \\
\hline $\begin{array}{l}\text { Age at first diagnosis of BD, } \\
\text { mean (SD); (range) }\end{array}$ & $\begin{array}{l}26.21 \pm 9.79 \\
(13-59)\end{array}$ & $\begin{array}{l}25.58 \pm 7.68 \\
(13-42)\end{array}$ & $\begin{array}{l}27.18 \pm 12.76 \\
(14-59)\end{array}$ & $1.539(26)$ & ns \\
\hline BMI score, mean (SD) & $25.33 \pm 2.62$ & $25.17 \pm 2.85$ & $25.59 \pm 2.33$ & $0.610(26)$ & ns \\
\hline $\begin{array}{l}\text { Positive family history } \\
\text { for BD-II, N (\%) }\end{array}$ & $10(35.7 \%)$ & $6(60 \%)$ & $4(40 \%)$ & $0.003(1)$ & ns \\
\hline $\begin{array}{l}\text { First episode polarity } \\
\text { (depressive/hypomanic) }\end{array}$ & $24(85.7 \%) / 4(14.3 \%)$ & $14(82.4 \%) / 3(17.6 \%)$ & $10(90.9 \%) / I(9.1 \%)$ & $0.399(1)$ & ns \\
\hline $\begin{array}{l}\text { Reported number of depressive } \\
\text { episodes (previous } 5 \text { years)* }\end{array}$ & $\begin{array}{l}\text { None, } N=16(57.1 \%) \\
\leq 3, N=10(35.7 \%) \\
\geq 4, N=2(7.1 \%)\end{array}$ & $\begin{array}{l}\text { None, } N=9(52.9 \%) \\
\leq 3, N=7(4 \mid .2 \%) \\
\geq 4, N=I(5.9 \%)\end{array}$ & $\begin{array}{l}\text { None, } N=7(63.9 \%) \\
\leq 3, N=3(27.3 \%) \\
\geq 4, N=I(9.1 \%)\end{array}$ & $0.591(2)$ & ns \\
\hline $\begin{array}{l}\text { Duration of current depressive } \\
\text { episode days (SD); (range) }\end{array}$ & $25.64 \pm 18.54 ;(14-90)$ & $26.18 \pm 21.59 ;(14-90)$ & $24.82 \pm 13.47 ;(14-60)$ & $10.78 \mid(10)$ & ns \\
\hline HAM-D-I7 score (SD); (range) & $25.86 \pm 3.19 ;(|9-3|)$ & $26.53 \pm 2.76 ;(2 I-3 I)$ & $24.82 \pm 3.65 ;(|9-3|)$ & $14.374(10)$ & ns \\
\hline YMRS score (SD) & $3.46 \pm 1.57$ & $3.41 \pm 1.73$ & $3.54 \pm 1.37$ & $3.544(6)$ & ns \\
\hline PSQI score (SD) & $\mid 1.39 \pm 5.31$ & $10.70 \pm 4.62$ & $12.45 \pm 6.33$ & $12.453(12)$ & ns \\
\hline CGI-BP-S (SD) & $4.36 \pm 1.37$ & $3.94 \pm 1.14$ & $5 \pm 1.48$ & $5.372(6)$ & ns \\
\hline Lifetime axis-I co-morbidity & & & & & \\
\hline Generalized anxiety disorder & $6(21.4 \%)$ & $4(23.5 \%)$ & $2(18.2 \%)$ & $0.113(I)$ & ns \\
\hline Obsessive-compulsive disorder & 7 (25\%) & $3(17.6 \%)$ & $4(36.4 \%)$ & $\mathrm{I} .248(\mathrm{I})$ & ns \\
\hline Panic disorder & $5(17.9 \%)$ & $3(17.6 \%)$ & $2(18.2 \%)$ & $0.001(1)$ & ns \\
\hline Specific phobias & $8(26.6 \%)$ & $4(23.3 \%)$ & $4(36.4 \%)$ & $0.539(1)$ & ns \\
\hline Impulse control disorder & $4(14.3 \%)$ & $3(17.6 \%)$ & I (9.1\%) & $0.399(1)$ & ns \\
\hline Anorexia nervosa & I (3.6\%) & I (5.9\%) & 0 & $0.671(1)$ & ns \\
\hline Bulimia nervosa & $3(10.7 \%)$ & $2(11.8 \%)$ & I (9.1\%) & $0.050(1)$ & ns \\
\hline Binge eating disorder & $4(14.3 \%)$ & $3(17.6 \%)$ & I (9.1\%) & $0.399(1)$ & ns \\
\hline
\end{tabular}

Notes: For $\chi 2$ and relative, $P$-values refer to the comparison between the two groups, not versus the whole sample (+valproate vs +lithium). "Age at first diagnosis of BD" may differ from age at first medical consultation for major depression or from actual age of onset of BD. *Current MDE excluded.

Abbreviations: BMI, body mass index; CGI-BP-I/S, Clinical Global Impression/Severity scales for Bipolar Disorder; HAM-D-I7, Hamilton Depression Rating-Scale I7-item; MDE, major depressive episode; PSQI, Pittsburgh Sleep Quality Index; SD, standard deviation; YMRS, Young Mania Rating Scales.

observed in the intent to treat population $(24.32 \pm 2.26 \mathrm{vs}$ baseline $25.33 \pm 2.62$ ) regardless of the primary mood stabilizer treatment. Specifically, mean BMI scores at week 36 were $24.73 \pm 2.12$ among valproate treated subjects and $23.68 \pm 2.43$ among lithium treated subjects. Also, at week 36 , there was a trend toward a negative correlation between BMI and HAM-D-17 score $(\mathrm{r}=-0.16 ; P=\mathrm{ns})$. There was no correlation between BMI and PISQ ( $\mathrm{r}=-0.06 ; P=\mathrm{ns})$. Additional information about the trend of specific clinical variables within the trial is reported in Figure 1.

\section{Adverse events}

Four patients (14.28\% of the total) dropped out due to a treatment-related AE by week 6 . In the valproate group, these

Table 2 Comparison of clinical measures at week-6 of the study (last post-baseline value)

\begin{tabular}{|c|c|c|c|c|c|}
\hline & $\begin{array}{l}\text { Included set } \\
N=28\end{array}$ & $\begin{array}{l}\text { +valproate group } \\
N=17(60.7 \%)\end{array}$ & $\begin{array}{l}\text { +lithium group } \\
\mathbf{N}=1 \text { I (39.3\%) }\end{array}$ & $\begin{array}{l}F \text { or } \chi^{2} \\
(\mathrm{df}=2)\end{array}$ & $P$ \\
\hline HAM-D-I 7 mean score (SD) & I0.7| (4.52) & $10.23(3.99)$ & II.45 (5.35) & II.58 (I2) & ns \\
\hline YMRS mean score (SD) & $7.89(5.14)$ & $6.94(3.38)$ & $9.36(7.01)$ & $10.53 \mid(8)$ & ns \\
\hline BMI score, mean (SD) & $25.27(3.26)$ & $25.59(3.21)$ & $24.77(3.43)$ & $16.610(15)$ & ns \\
\hline CGI-BP-S mean (SD) & $4.18(1.28)$ & $3.82(1.13)$ & $4.73(1.35)$ & $4.742(5)$ & ns \\
\hline CGI-BP-I mean (SD) & $2.78(1.64)$ & $2.88(1.87)$ & $2.64(1.29)$ & $2.306(6)$ & ns \\
\hline PSQI mean (SD) & $4.61(1.42)$ & $4.88(I .4 I)$ & $4.18(1.40)$ & $3.835(5)$ & ns \\
\hline
\end{tabular}

Abbreviations: BMI, body mass index; CGI-BP-I/S, Clinical Global Impression/Severity scales for Bipolar Disorder; HAM-D-I7, Hamilton Depression Rating-Scale I7-item; PSQI, Pittsburgh Sleep Quality Index; SD, standard deviation; YMRS, Young Mania Rating Scales. 


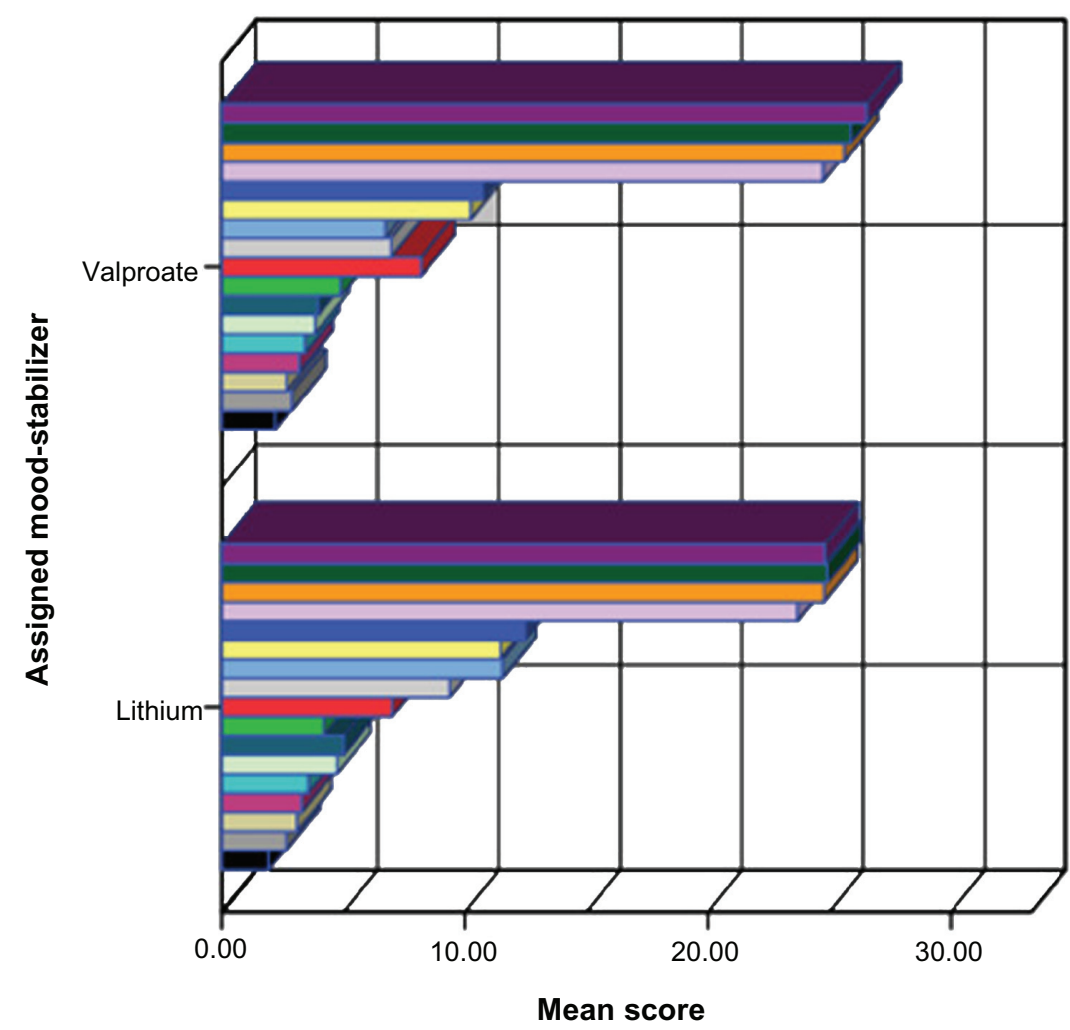

CGI_BP_I_36

CGI_BP_I_W6

PSQI_W36

CGI_BP_SW36

YMRS_baseline

CGI_BP_S_W6

1CGI_BP_S_baseline

PSQI W6

HAM_D_17_W36

YMRS_W36

YMRS_W36

$\square$ HAM_D_17_W6

PSQI_baseline

BMI_week_36

BMI_week_6

BMI_baseline

HAM_D_17_baseline

Mean score

Figure I Trend of different rating and clinical parameters at weeks 6 and 36 between the two groups.

Note: While the figure fails to show any substantial differences between groups, this highlights the fact that the effect of agomelatine add-on therapy was substantially maintained within week 6 and week 36, independent of the ongoing mood stabilizer treatment.

Abbreviations: BMI, body mass index; CGI-BP-I/S, Clinical Global Impression/Severity scales for Bipolar Disorder; HAM-D-I7, Hamilton Depression Rating-Scale I7-item; PSQI, Pittsburgh Sleep Quality Index; YMRS, Young Mania Rating Scales.

included a single case each of pseudo-vertigo and hypomania; in the lithium group, these included a single case of insomnia and mania $($ YMRS $=30)$.

Two additional cases left the study at week 36 due to hypomania. These included one each in both the valproate $($ YMRS $=17)$ and lithium $($ YMRS $=16)$ treated groups. Notably, whenever an AE occurred, this was judged as severe and considered responsible for drop out.

\section{Discussion}

\section{Overview and limits of the study}

Our results suggest that adjunctive agomelatine may be useful in the treatment of acute depression in BD-II. During both the short- and longer-term periods of the trial, agomelatine treatment was associated with improvements in depression and sleep quality and was well tolerated.

Nonetheless, the study was limited by several important factors that warrant discussion, especially in light of the potential "publication and outcome reporting" biases that have arisen regarding randomized controlled studies involving agomelatine in the treatment of MDD. ${ }^{29}$

Additionally, the pharmacodynamics of agomelatine need to be better characterized in human samples. In fact, by inhibiting 5-HT2C receptors, agomelatine secondarily increases norepinephrine and dopamine in the frontal cortex of the brain of animals, while the drug binding and coupling profiles of h5-HT2B and h5-HT2C receptors are similar, and agomelatine also blocked 5-HT-induced [3H]PI depletion at h5-HT2B sites. ${ }^{30}$ However, 5-HT2B receptors are poorly represented in the central nervous system, wherein their functional significance remains substantially obscure. ${ }^{31}$

Due to safety reasons and the preliminary nature of the study, raters also participated in the clinical management and were therefore not blind to treatment assignments ("measurement bias"). Moreover, because agomelatine is not yet supplied for free by the National Health System in Italy (unlike many medications), this naturalistic study may suffer from an additional selection bias, favoring recruitment 
of patients who were more financially stable and/or motivated for treatment, potentially influencing both the drop-out rate and medication adherence ("under/over-reporting bias"), especially in the optional 30 week extension period. Despite these limitations, our results should stimulate further investigation of agomelatine and BD-II.

On the other hand, since the ultimate goal of treatment in "acute" bipolar depression should be establishing long-term mood stability, ${ }^{32}$ the lack of additional follow up, ideally beyond 52 weeks, ${ }^{11}$ needs to be noted, although very few pilot studies would indeed follow this criterion. However, it is worthy of notice that during both the acute and extension periods of the trial, adjunctive agomelatine treatment was associated with improvement in depression, with favorable safety and tolerability profiles, including sensitive issues such as liver (there was no clinically relevant enzyme modification within the trial) and sexual function, ${ }^{29,33,34}$ although these latter outcomes were not assessed by ad hoc instruments, and improvement of subjective sleep quality - when initially impaired - was not assessed by actigraphic techniques or by other objective neurophysiological measurements due to the very preliminary nature of the study, whereas lithium or valproate may have contributed both to the antidepressant response and, possibly, to modulation of MT1/MT2 melatonergic receptors as already documented in animal models..$^{35,36}$ Finally, the fact that the mean duration of depression was less than 4 weeks (with a lower range of 2 weeks) cannot exclude the chance of spontaneous improvement due to the natural course of depression for those subjects judged as "responders"; equally, the eventual predictive role of anxious co-morbidity (when present) could not be evinced at this time due to the small sample size and methodological limits of this preliminary study, although agomelatine has been anecdotally reported to have a promising modulating role in anxious disorders. ${ }^{37-43}$

\section{Agomelatine, sleep, and depression}

The effects of agomelatine on sleep have already been documented by different studies on MDD samples. Among others, a comparative study with venlafaxine highlighted a statistically significant improvement of sleep with agomelatine, ${ }^{44}$ a faster improvement of the "circadian rest-activity cycle" compared to sertraline, ${ }^{45}$ and a better rapid eye movement profile - but not short wave sleep profile, possibly due to 5 -HT2C antagonism in comparison to escitalopram, ${ }^{46}$ although the degree to which 5-HT2C receptor antagonism explains or contributes to the antidepressant or sleep effect of agomelatine has been questioned in humans. ${ }^{47}$
Sleep disturbances are a core aspect of BD and may often predict subsequent manic switch. ${ }^{48}$ In our study and in others, agomelatine led to sustained subjective improvements in sleep quality in association with either lithium or valproate, beginning as early as 2 weeks into treatment. The concomitant use of benzodiazepines during the first 2 weeks may have influenced these results, but is unlikely to account for the effect since only a minority patients used these medications $(n=3 / 28 ; 10.7 \%)$, and no patients used them beyond the second week. Improved sleep quality may have important clinical implications for BD-II, but may not necessarily improve mood. ${ }^{49}$ While insomnia has been reported as a major predictor of depression, ${ }^{50}$ abnormalities in sleep architecture, including disturbances of sleep consolidation, slow-wave sleep, and rapid eye movement sleep are common during antidepressant treatments, suggesting sleep quality and mood state are dissociable. ${ }^{51,52}$ Paradoxically, four patients (14.3\%) experienced insomnia while taking agomelatine. This problem was effectively managed after exclusion from the study by switching the time of agomelatine administration from bedtime to early morning, without any subsequent manic switch. While not described in previous trials, this unexpected insomnia may be related to circadian phase abnormalities associated with depression. In seasonal depression, most patients are thought to be phase delayed and respond to the phase advancing effects of evening melatonin. In contrast, $\sim 30 \%$ may be phase advanced. ${ }^{53}$ In these latter cases, evening melatonin receptor stimulation may lead to a worsening of the circadian abnormality by further advancing phase, perhaps disrupting sleep onset and causing nighttime insomnia. If these findings generalize to bipolar depression, among the minority of subjects with advanced phase, morning agomelatine would correct the abnormality by delaying phase to a more optimal time.

\section{Adverse events and manic switch}

While relatively few in number, our study did have AEs to report, including four mood switches to (hypo-) mania. The rate of manic/hypomanic switch was lower than expected based on previous clinical experience with other antidepressants added to mood stabilizers in the treatment of acute depression in BD-II, yet was still remarkable compared to other established antidepressants. ${ }^{54}$ Nonetheless, the profile of agomelatine with regard to manic switching is consistent with preliminary reports from BD-I; ${ }^{10}$ since the safety of antidepressants in bipolar depression is of great interest in modern clinical psychiatry, further research on this issue is needed for agomelatine to reliably compare corresponding 
data coming from controlled trials on other antidepressants, ideally looking at long-term treatment compliance and stability. ${ }^{55}$

The occurrence of "pseudo-vertigo" (dizziness not involving a sense of rotation, which is common in the course of panic disorders, hyperventilation, and orthostatic hypotension) in three patients was another unexpected $\mathrm{AE}$ that was encountered. Of note, a previous case report suggested an interaction between agomelatine and the melatonergic neurons of the cerebellum in a minority of sensitive individuals. ${ }^{38}$ Larger studies are required to determine the rate of $\mathrm{AE}$ associated with this problem.

\section{Implications for the circadian rhythm hypothesis of BD}

With the associated disruptions in sleep and daily activity cycles, circadian rhythm abnormalities have been proposed to play a role in the etiology of mood disorders, including BD. Both lithium and valproate, the mood stabilizers used in our study, have effects on circadian rhythms, ${ }^{56-58}$ and genetic variants in clock genes have been associated with lithium response. ${ }^{59} \mathrm{BD}$ patients have been reported to be particularly sensitive to environmental events, ${ }^{60,61}$ a feature that has also been associated with circadian instability, ${ }^{62}$ suggesting that biological rhythms play a critical role in the emotional dysregulation at the center of $\mathrm{BD} .{ }^{19,63,64}$ Central to the circadian effects on mood is the availability of light. Differential outcomes in antidepressant response are associated with specific changes in retinal physiology, suggesting that proper timing of light input into the central nervous system may be an important aspect of antidepressant response. ${ }^{65}$

In this context, it is interesting to consider the implications of our agomelatine findings with respect to the circadian clock hypothesis of mood disorders. We found changes in sleep quality and BMI, the latter presumably reflecting differences in dietary intake and/or motor activity. It is interesting to note that regardless of the use of drugs that affect the clock in distinct ways (lithium and valproate), the effects of agomelatine on rhythmically influenced behaviors did not differ by the concomitant mood stabilizer. Of interest, previous reports have described melatonergic neurons outside the central nervous system, including those in the gastrointestinal tract, that are influenced both by light/dark cycles and environmental stressors. ${ }^{66-69}$ Collectively, these findings lend support to the supposed interaction between melatonergic regulation on mood and the "gut-clock". ${ }^{70}$ If further evidence supports the hypothesis that agomelatine functions as core "rhythm regulator," a therapeutic role for those $\mathrm{BD}$ patients with prominent imbalances in eating rhythms, and may extend the concept of rhythm disturbances in mood disorder to include feeding behavior and metabolic activity in addition to sleep/wake behavior. ${ }^{72-75}$ This could be in marked contrast to standard antidepressants, with their propensity toward causing weight gain via serotonergic stimulation of 5-HT2A receptors rather than selective antagonism of 5-HT2C. ${ }^{9,51,76,77}$ It will be of interest in the future to determine whether agomelatine affects excessive or atypical eating behaviors in the context of depression, especially in the view that animal studies have reported that 5-HT2B agonists concur with hyperphagia and reduce grooming in rodents, ${ }^{78}$ whereas stimulation of 5-HT2B sites exerts actions in animal peripheral tissues, especially in development. However, there is no evidence for a functional effect of antagonists at these sites ${ }^{79}$ and agomelatine is yet to be characterized in this regard in human samples.

\section{Concluding remarks}

Adjunctive agomelatine treatment with lithium or valproate in the acute phase of BD-II major depression led to substantial positive results in our preliminary open label trial. Large double-blind randomized controlled studies are warranted and will be essential to providing more definitive evidence of the efficacy, safety, and optimal dose-range profile compared to MDD usage. ${ }^{80}$

\section{Disclosure}

The authors report no conflicts of interest in this work.

\section{References}

1. APA. Diagnostic and Statistical Manual for Mental Disorders, 4th ed. Washington, DC: American Psychiatric Association; 1994.

2. Ketter TA, Calabrese JR. Stabilization of mood from below versus above baseline in bipolar disorder: a new nomenclature. J Clin Psychiatry. 2002; 63(2):146-151.

3. Swartz HA, Thase ME. Pharmacotherapy for the treatment of acute bipolar II depression: current evidence. The Journal of Clinical Psychiatry. 2011;72(3):356-366.

4. Rybakowski JK. Bipolarity and inadequate response to antidepressant drugs: clinical and psychopharmacological perspective. Journal of Affective Disorders. 2012;136(1-2):e13-e19.

5. Fornaro M, Martino M, De Pasquale C, Moussaoui D. The argument of antidepressant drugs in the treatment of bipolar depression: mixed evidence or mixed states? Expert Opinion on Pharmacotherapy. 2012;13(14):2037-2051.

6. den Boer JA, Bosker FJ, Meesters Y. Clinical efficacy of agomelatine in depression: the evidence. International Clinical Psychopharmacology. 2006;21(Suppl 1):S21-S24.

7. Montgomery SA, Kasper S. Severe depression and antidepressants: focus on a pooled analysis of placebo-controlled studies on agomelatine. International Clinical Psychopharmacology. 2007;22(5):283-291.

8. Kennedy SH, Young AH, Blier P. Strategies to achieve clinical effectiveness: refining existing therapies and pursuing emerging targets. Journal of Affective Disorders. 2011;132(Suppl 1):S21-S28. 
9. Fornaro M, Prestia D, Colicchio S, Perugi G. A systematic, updated review on the antidepressant agomelatine focusing on its melatonergic modulation. Current Neuropharmacology. 2010;8(3):287-304.

10. Calabrese JR, Guelfi JD, Perdrizet-Chevallier C. Agomelatine adjunctive therapy for acute bipolar depression: preliminary open data. Bipolar Disorders. 2007;9(6):628-635.

11. Eppel AB. Agomelatine adjunctive therapy for acute bipolar depression: preliminary open data. Bipolar Disorders. 2008;10(6):749-750.

12. Angst J, Marneros A. Bipolarity from ancient to modern times: conception, birth and rebirth. Journal of Affective Disorders. 2001;67(1-3): 3-19.

13. Lopez-Munoz F, Alamo C. Cartesian theories on the passions, the pineal gland and the pathogenesis of affective disorders: an early forerunner. Psychological Medicine. 2011;41(3):449-451.

14. Wehr TA, Goodwin FK. Rapid cycling in manic-depressives induced by tricyclic antidepressants. Archives of General Psychiatry. 1979;36(5): $555-559$.

15. McCarthy MJ, Welsh DK. Cellular circadian clocks in mood disorders. Journal of Biological Rhythms. 2012;27(5):339-352.

16. Jackson A, Cavanagh J, Scott J. A systematic review of manic and depressive prodromes. Journal of Affective Disorders. 2003;74(3): 209-217.

17. Monteleone P, Martiadis V, Maj M. Circadian rhythms and treatment implications in depression. Progress in Neuro-Psychopharmacology and Biological Psychiatry. 2011;35(7):1569-1574.

18. Racagni G, Riva MA, Molteni R, et al. Mode of action of agomelatine: synergy between melatonergic and 5-HT2C receptors. The world journal of biological psychiatry. The Official Journal of the World Federation of Societies of Biological Psychiatry. 2011;12(8):574-587.

19. Murray G, Harvey A. Circadian rhythms and sleep in bipolar disorder. Bipolar Disorders. 2010;12(5):459-472.

20. Mazza M, Mandelli L, Martinotti G, et al. Further evidence supporting the association between $5 \mathrm{HTR} 2 \mathrm{C}$ gene and bipolar disorder. Psychiatry Research. 2010;180(2-3):151-152.

21. Fornaro M, Aguglia E, Dell'Osso L, Perugi G. Could the underestimation of bipolarity obstruct the search for novel antidepressant drugs? Expert Opinion on Pharmacotherapy. 2011;12(18):2817-2831.

22. First MB, Spitzer RI, Gibbon M, Williams BJW. Structured Clinical Interview for DSM-IV Axis I Disorders. Washington, DC: American Psychiatric Press; 1997.

23. Hamilton M. Development of a rating scale for primary depressive illness. The British Journal of Social and Clinical Psychology. 1967;6(4):278-296.

24. Spearing MK, Post RM, Leverich GS, Brandt D, Nolen W. Modification of the Clinical Global Impressions (CGI) Scale for use in bipolar illness (BP): the CGI-BP. Psychiatry Research. 1997;73(3): 159-171.

25. Young RC, Biggs JT, Ziegler VE, Meyer DA. A rating scale for mania: reliability, validity and sensitivity. The British Journal of Psychiatry: The Journal of Mental Science. 1978;133:429-435.

26. Buysse DJ, Reynolds CF 3rd, Monk TH, Berman SR, Kupfer DJ. The Pittsburgh Sleep Quality Index: a new instrument for psychiatric practice and research. Psychiatry Research. 1989;28(2):193-213.

27. Julious SA. Sample size of 12 per group rule of thumb for a pilot study. Pharmaceutical Statistics. 2005;4(4):287-291.

28. Muller MJ, Himmerich H, Kienzle B, Szegedi A. Differentiating moderate and severe depression using the Montgomery-Asberg Depression Rating Scale (MADRS). Journal of Affective Disorders. 2003;77(3): 255-260.

29. Howland RH. Publication bias and outcome reporting bias: agomelatine as a case example. Journal of Psychosocial Nursing and Mental Health Services. 2011;49(9):11-14.

30. Millan MJ, Gobert A, Lejeune F, et al. The novel melatonin agonist agomelatine (S20098) is an antagonist at 5-hydroxytryptamine2C receptors, blockade of which enhances the activity of frontocortical dopaminergic and adrenergic pathways. The Journal of Pharmacology and Experimental Therapeutics. 2003;306(3):954-964.
31. Duxon MS, Kennett GA, Lightowler S, Blackburn TP, Fone KC. Activation of 5-HT2B receptors in the medial amygdala causes anxiolysis in the social interaction test in the rat. Neuropharmacology. 1997;36(4-5):601-608.

32. Malhi GS, Adams D, Berk M. Medicating mood with maintenance in mind: bipolar depression pharmacotherapy. Bipolar Disorders. 2009;11(Suppl 2):55-76.

33. Montgomery SA, Kennedy SH, Burrows GD, Lejoyeux M, Hindmarch I. Absence of discontinuation symptoms with agomelatine and occurrence of discontinuation symptoms with paroxetine: a randomized, doubleblind, placebo-controlled discontinuation study. International Clinical Psychopharmacology. 2004;19(5):271-280.

34. Montejo A, Majadas S, Rizvi SJ, Kennedy SH. The effects of agomelatine on sexual function in depressed patients and healthy volunteers. Human Psychopharmacology. 2011;26(8):537-542.

35. Niles LP, Sathiyapalan A, Bahna S, Kang NH, Pan Y. Valproic acid upregulates melatonin MT1 and MT2 receptors and neurotrophic factors $\mathrm{CDNF}$ and MANF in the rat brain. The International Journal of Neuropsychopharmacology/Official Scientific Journal of the Collegium Internationale Neuropsychopharmacologicum. 2012;15(9):1343-1350.

36. Hallam KT, Olver JS, Horgan JE, McGrath C, Norman TR. Low doses of lithium carbonate reduce melatonin light sensitivity in healthy volunteers. The International Journal of Neuropsychopharmacology/ Official Scientific Journal of the Collegium Internationale Neuropsychopharmacologicum. 2005;8(2):255-259.

37. Levitan MN, Papelbaum M, Nardi AE. A review of preliminary observations on agomelatine in the treatment of anxiety disorders. Experimental and Clinical Psychopharmacology. 2012;20(6):504-509.

38. Fornaro M. Switching from serotonin reuptake inhibitors to agomelatine in patients with refractory obsessive-compulsive disorder: a 3 month follow-up case series. Annals of General Psychiatry. 2011;10(1):5.

39. Fornaro M. Agomelatine in the treatment of panic disorder. Progress in Neuro-Psychopharmacology and Biological Psychiatry. 2011;35(1): 286-287.

40. De Berardis D, Serroni N, Marini S, et al. Agomelatine augmentation of escitalopram therapy in treatment-resistant obsessive-compulsive disorder: a case report. Case Reports in Psychiatry. 2012;2012:642-752.

41. De Berardis D, Serroni N, Campanella D, et al. A case of obsessive-compulsive disorder successfully treated with agomelatine monotherapy. Journal of Clinical Psychopharmacology. 2012;32(2):289-290.

42. De Berardis D, Serroni N, Marini S, Moschetta FS, Martinotti G, Di Giannantonio M. Agomelatine for the treatment of posttraumatic stress disorder: a case report. Annals of Clinical Psychiatry: Official Journal of the American Academy of Clinical Psychiatrists. 2012;24(3):241-242.

43. Crippa JA, Hallak JE, Zuardi AW, Chagas MH, Quevedo J, Nardi AE. Agomelatine in the treatment of social anxiety disorder. Progress in Neuro-Psychopharmacology and Biological Psychiatry. 2010;34(7): 1357-1358.

44. Lemoine P, Guilleminault C, Alvarez E. Improvement in subjective sleep in major depressive disorder with a novel antidepressant, agomelatine: randomized, double-blind comparison with venlafaxine. The Journal of Clinical Psychiatry. 2007;68(11):1723-1732.

45. Kasper S, Hajak G, Wulff K, et al. Efficacy of the novel antidepressant agomelatine on the circadian rest-activity cycle and depressive and anxiety symptoms in patients with major depressive disorder: a randomized, double-blind comparison with sertraline. The Journal of Clinical Psychiatry. 2010;71(2):109-120.

46. Quera-Salva MA, Hajak G, Philip P, et al. Comparison of agomelatine and escitalopram on nighttime sleep and daytime condition and efficacy in major depressive disorder patients. International Clinical Psychopharmacology. 2011;26(5):252-262.

47. Sharpley AL, Rawlings NB, Brain S, McTavish SF, Cowen PJ. Does agomelatine block 5-HT2C receptors in humans? Psychopharmacology. 2011;213(2-3):653-655.

48. Colombo C, Benedetti F, Barbini B, Campori E, Smeraldi E. Rate of switch from depression into mania after therapeutic sleep deprivation in bipolar depression. Psychiatry Research. 1999;86(3):267-270. 
49. Rojo JE, Gibert K, Cobo J, Rodriguez-Cano E, Vallejo J. Onset of antidepressant action: a pharmacological question? Human Psychopharmacology. 2005;20(6):425-433.

50. Baglioni C, Battagliese G, Feige B, et al. Insomnia as a predictor of depression: a meta-analytic evaluation of longitudinal epidemiological studies. Journal of Affective Disorders. 2011;135(1-3):10-19.

51. Matthews PR. Efficacy of antidepressants: similar but different. The International Journal of Neuropsychopharmacology/Official Scientific Journal of the Collegium Internationale Neuropsychopharmacologicum 2011;14(10):1433-1437.

52. Wichniak A, Wierzbicka A, Jernajczyk W. Sleep and antidepressant treatment. Current Pharmaceutical Design. 2012;18(36):5802-5817.

53. Lewy AJ, Lefler BJ, Emens JS, Bauer VK. The circadian basis of winter depression. Proceedings of the National Academy of Sciences of the United States of America. 2006;103(19):7414-7419.

54. Leverich GS, Altshuler LL, Frye MA, et al. Risk of switch in mood polarity to hypomania or mania in patients with bipolar depression during acute and continuation trials of venlafaxine, sertraline, and bupropion as adjuncts to mood stabilizers. The American Journal of Psychiatry. 2006;163(2):232-239.

55. Ghaemi SN, Ostacher MM, El-Mallakh RS, et al. Antidepressant discontinuation in bipolar depression: a Systematic Treatment Enhancement Program for Bipolar Disorder (STEP-BD) randomized clinical trial of long-term effectiveness and safety. The Journal of Clinical Psychiatry. 2010;71(4):372-380.

56. Kripke DF, Judd LL, Hubbard B, Janowsky DS, Huey LY. The effect of lithium carbonate on the circadian rhythm of sleep in normal human subjects. Biological Psychiatry. 1979;14(3):545-548.

57. Li J, Lu WQ, Beesley S, Loudon AS, Meng QJ. Lithium impacts on the amplitude and period of the molecular circadian clockwork. PloS One. 2012;7(3):e33292.

58. Johansson AS, Brask J, Owe-Larsson B, Hetta J, Lundkvist GB. Valproic acid phase shifts the rhythmic expression of Period2::Luciferase. Journal of Biological Rhythms. 2011;26(6):541-551.

59. McCarthy MJ, Nievergelt CM, Shekhtman T, Kripke DF, Welsh DK, Kelsoe JR. Functional genetic variation in the Rev-Erbalpha pathway and lithium response in the treatment of bipolar disorder. Genes, Brain, and Behavior. 2011;10(8):852-861.

60. Gruber J, Miklowitz DJ, Harvey AG, et al. Sleep matters: sleep functioning and course of illness in bipolar disorder. Journal of Affective Disorders. 2011;134(1-3):416-420.

61. Scott J. Clinical parameters of circadian rhythms in affective disorders. European Neuropsychopharmacology: The Journal of the European College of Neuropsychopharmacology. 2011;21(Suppl 4):S671-S675.

62. Murray G, Allen NB, Trinder J, Burgess H. Is weakened circadian rhythmicity a characteristic of neuroticism? Journal of Affective Disorders. 2002;72(3):281-289.

63. Bullock B, Judd F, Murray G. Social rhythms and vulnerability to bipolar disorder. Journal of Affective Disorders. 2011;135(1-3):384-388.

64. Ehlers CL, Frank E, Kupfer DJ. Social zeitgebers and biological rhythms. A unified approach to understanding the etiology of depression. Archives of General Psychiatry. 1988;45(10):948-952.

65. Fornaro M, Bandini F, Ogliastro C, et al. Electroretinographic assessment in major depressed patients receiving duloxetine: might differences between responders and non-responders indicate a differential biological background? Journal of Affective Disorders. 2011;135(1-3): 154-159.

Neuropsychiatric Disease and Treatment

\section{Publish your work in this journal}

Neuropsychiatric Disease and Treatment is an international, peerreviewed journal of clinical therapeutics and pharmacology focusing on concise rapid reporting of clinical or pre-clinical studies on a range of neuropsychiatric and neurological disorders. This journa is indexed on PubMed Central, the 'PsycINFO' database and CAS.
66. Konturek PC, Brzozowski T, Konturek SJ. Gut clock: implication of circadian rhythms in the gastrointestinal tract. Journal of Physiology and Pharmacology: An Official Journal of the Polish Physiological Society. 2011;62(2):139-150.

67. Nisembaum LG, Velarde E, Tinoco AB, et al. Light-dark cycle and feeding time differentially entrains the gut molecular clock of the goldfish (Carassius auratus). Chronobiology International. 2012;29(6):665-673.

68. Huang W, Ramsey KM, Marcheva B, Bass J. Circadian rhythms, sleep, and metabolism. The Journal of Clinical Investigation. 2011;121(6): 2133-2141.

69. Reiter RJ, Rosales-Corral S, Coto-Montes A, et al. The photoperiod, circadian regulation and chronodisruption: the requisite interplay between the suprachiasmatic nuclei and the pineal and gut melatonin. Journal of Physiology and Pharmacology: An Official Journal of the Polish Physiological Society. 2011;62(3):269-274.

70. Albrecht U. Circadian rhythms and sleep - the metabolic connection. Pflugers Archiv: European Journal Of Physiology. 2012;463(1): 23-30

71. Fountoulakis KN. Disruption of biological rhythms as a core problem and therapeutic target in mood disorders: the emerging concept of 'rhythm regulators'. Annals of General Psychiatry. 2010;9:3.

72. Fornaro M, Perugi G, Gabrielli F, et al. Lifetime co-morbidity with different subtypes of eating disorders in 148 females with bipolar disorders. Journal of Affective Disorders. 2010;121(1-2):147-151.

73. Muhlhans B, Olbrich K, de Zwaan M. Night eating syndrome and nocturnal eating - what is it all about? Psychotherapie, Psychosomatik, Medizinische Psychologie. 2009;59(2):50-56.

74. Goel N, Stunkard AJ, Rogers NL, et al. Circadian rhythm profiles in women with night eating syndrome. Journal of Biological Rhythms. 2009;24(1):85-94.

75. McElroy SL, Frye MA, Hellemann G, et al. Prevalence and correlates of eating disorders in 875 patients with bipolar disorder. Journal of Affective Disorders. 2011;128(3):191-198.

76. Montgomery SA. Why do we need new and better antidepressants? International Clinical Psychopharmacology. 2006;21(Suppl 1): $\mathrm{S} 1-\mathrm{S} 10$.

77. Kasper S, Corruble E, Hale A, Lemoine P, Montgomery SA, QueraSalva MA. Antidepressant efficacy of agomelatine versus SSRI/SNRI results from a pooled analysis of head-to-head studies without a placebo control. International Clinical Psychopharmacology. 2012;28(1): $12-9$.

78. Kennett GA, Ainsworth K, Trail B, Blackburn TP. BW 723C86, a 5-HT2B receptor agonist, causes hyperphagia and reduced grooming in rats. Neuropharmacology. 1997;36(2):233-239.

79. Nebigil CG, Etienne N, Schaerlinger B, Hickel P, Launay JM, Maroteaux L. Developmentally regulated serotonin 5-HT2B receptors. International Journal of Developmental Neuroscience: The Official Journal of the International Society for Developmental Neuroscience. 2001;19(4):365-372.

80. Loo H, Hale A, D'Haenen H. Determination of the dose of agomelatine, a melatoninergic agonist and selective 5-HT(2C) antagonist, in the treatment of major depressive disorder: a placebo-controlled dose range study. International Clinical Psychopharmacology. 2002;17(5): $239-247$.

The manuscript management system is completely online and includes a very quick and fair peer-review system, which is all easy to use. Visit http://www.dovepress.com/testimonials.php to read real quotes from published authors. 